\title{
ENSAIO FOTOGRÁFICO Cuia pitinga, natureza e cultura da várzea amazônica
}

\author{
Luciana Gonçalves de Carvalho ${ }^{1}$ \\ Carlos de Matos Bandeira ${ }^{2}$ \\ Alexandre Nazareth da Rocha ${ }^{3}$ \\ Universidade Federal do Oeste do Pará
}

Resumo: Este ensaio fotográfico revela cenas cotidianas registradas em comunidades de várzea da região do Aritapera, em Santarém, Pará. Essa região é particularmente renomada, no estado, pela reputação de sua produção de cuias, quer sejam pitingas (brancas, sem pigmentação), quer sejam tingidas e ornamentadas com incisões. Atraídas pela constante presença das cuias pitingas, isto é, não pigmentadas, em diferentes cenários da várzea, as câmeras percorrem o ambiente doméstico de algumas das mulheres responsáveis por transformar os frutos da cuieira (Crescentia cujete) em objetos bons para ver, usar e pensar. Transitando por tempos e espaços distintos, seguindo fluxos entre a natureza e a cultura, as lentes demonstram que as cuias pitingas são produtos de um requintado pensamento selvagem, capazes de intermediar materiais e simbólicas trocas entre humanos e não humanos.

Palavras-chave: artesanato; cuias; cuia pitinga; Santarém (PA).

${ }^{1}$ Doutora em Antropologia, professora do PPGSND/Ufopa, do PPGCS/Ufopa e do PPGSA/UFPA. Autora do Dossiê de Registro do Modo de Fazer Cuias no Baixo Amazonas como Patrimônio Cultural do Brasil.

${ }^{2}$ Fotógrafo, autor de registros fotográficos e audiovisuais dos inventários de referências culturais da Festa do Sairé e do Modo de Fazer Cuias no Baixo Amazonas.

3 Produtor cultural, coordenou o Festival de Cuias do Aritapera em 2018 e outros projetos no campo do patrimônio cultural imaterial junto ao CNFCP/Iphan e ao Iphan-PA. 


\title{
Cuia pitinga, nature and culture of the Amazon varzea
}

\begin{abstract}
This photographic essay reveals daily scenes recorded in floodplain communities of the Aritapera region, in Santarém, Pará. This region is particularly renowned in the state for its reputation for its production of gourds, whether white (pigmentation) or dyed and ornamented with incisions. Attracted by the constant presence of pitingas, non-pigmented gourds, in different scenarios of the varzea, the cameras go through the domestic environment of some of the women responsible for transforming the fruits of the cuieira (Crescentia cujete) into good objects to see, to use and to think about. Transiting through different times and spaces, following flows between nature and culture, the lenses demonstrate that the pitingas gourds are products of refined savage thinking, capable of mediating materials and symbolic exchanges between humans and non-humans.
\end{abstract}

Keywords: handicraft; gourds; cuia pitinga; Santarém (PA).

\section{Cuia pitinga, naturaleza y cultura de la várzea amazonica}

\begin{abstract}
Resumen: Este ensayo fotográfico revela escenas cotidianas registradas en comunidades de várzea de la región del Aritapera, en Santarém, Pará. Esta región es particularmente renombrada, en el estado, por la reputación de su producción de cuñas, ya sean pitingas (blancas, sí pigmentación), ya sean teñidas y ornamentadas con incisiones. Atraídas por la constante presencia de las cuias pitingas, en los diferentes escenarios de la várzea, las cámaras recorren el ambiente doméstico de algunas de las mujeres responsables de transformar los frutos de Crescentia cujete en objetos buenos para ver, usar y pensar. Transitando por tiempos y espacios distintos, siguiendo flujos entre la naturaleza y la cultura, las lentes demuestran que las cuias pitingas son productos de un refinado pensamiento salvaje, capaces de intermediar intercambios materiales y simbólicos entre humanos y no humanos.
\end{abstract}

Palavras-chave: artesanía; calabazas; cuia pitinga; Santarém (PA). 
$\mathrm{C}$ laro ou branco, sem pigmentação - eis o significado de pitinga, termo comum do vocabulário ribeirinho do Norte do Brasil. Nas várzeas do Baixo Amazonas, toda casa possui cuias pitingas a servirem de baldes, coiós, copos, tigelas e vasilhas para as mais diversas finalidades (CARVALHO, 2011). Feitas dos frutos lustrosos e verdejantes das cuieiras (Crescentia cujete) cortados em bandas ou em formatos assimétricos, elas passam de mão em mão e ocupam os diferentes espaços das moradias à beira-rio, inclusive as pontes lançadas aos alagadiços e as canoas, que são como extensão dos pés dos varzeiros durante as enchentes.

Neste ensaio, são reveladas cenas cotidianas presenciadas em quatro anos de convívio nas comunidades da região do Aritapera, em Santarém, Pará. Artesãs dessa região são particularmente renomadas, no estado, pela reputação da sua produção de cuias tingidas e decoradas com incisões, as quais, desde tempos remotos, ultrapassam as fronteiras locais para alcançar mercados no Brasil e no exterior (HARTMANN, 1988; FERREIRA, 1876). Mas, tão fartas são as cuieiras do Aritapera, que muitos frutos se aproveitam para uso próprio, com ou sem pigmentação e ornamentos gráficos. Jamais sem beleza.

Atraídas pela constante presença das cuias pitingas em diferentes cenários, as câmeras percorrem o ambiente doméstico de algumas das mulheres responsáveis por transformar aqueles frutos em objetos bons para ver, usar e pensar (PAZ, 1991; LÉVI-STRAUSS, 1989). Transitando por tempos e espaços distintos, seguindo fluxos entre a natureza e a cultura, as lentes demonstram que as cuias pitingas são produtos de um requintado pensamento selvagem (LÉVI-STRAUSS, 1989), capazes de intermediar materiais e simbólicas trocas entre humanos e não humanos (ANDRADE, 1939). 


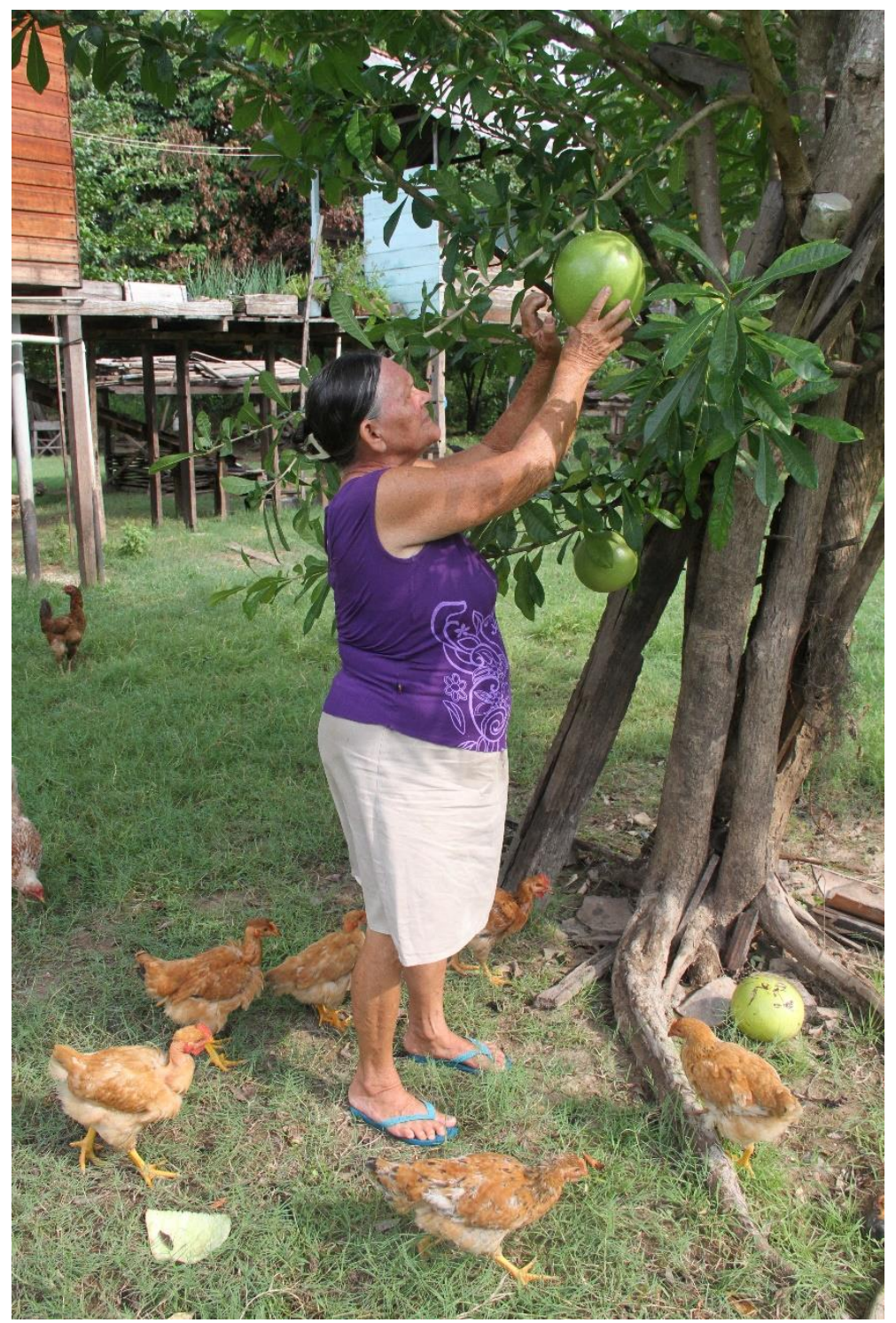

Foto 1 - A primeira etapa de trabalho no artesanato de cuias é a colheita dos frutos maduros das cuieiras. Quando pendem dos galhos mais baixos, podem ser apanhados com facilidade, como demonstra a artesã Cecília Corrêa. O miolo ou bucho dos frutos é usado como ração para animais domésticos. Autor: Carlos de Matos Bandeira, Centro do Aritapera, 2014. 


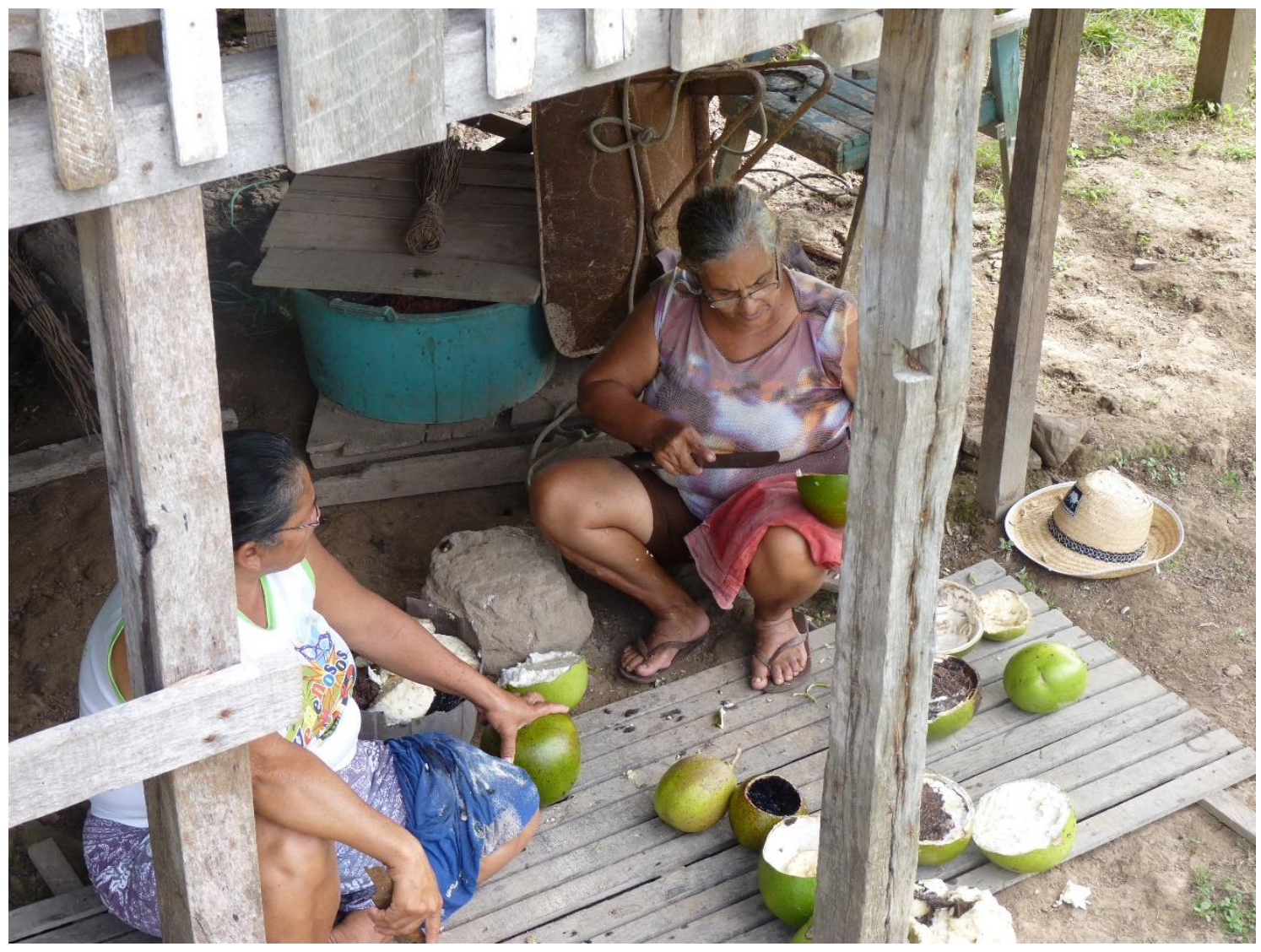

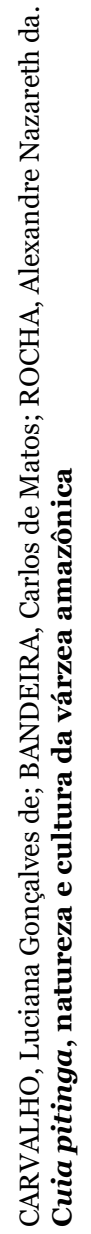

na Associação das Artesãs Ribeirinhas de Santarém, que reúne produtoras de cuias da região do Aritapera. Sob o assoalho da casa de palafita, típica da várzea, elas cortam e dividem os frutos para posterior limpeza, lixamento e alisamento de suas bandas, até se tornarem cuias pitingas. Autor: Alexandre Nazareth da Rocha, Carapantuba, 2011. 


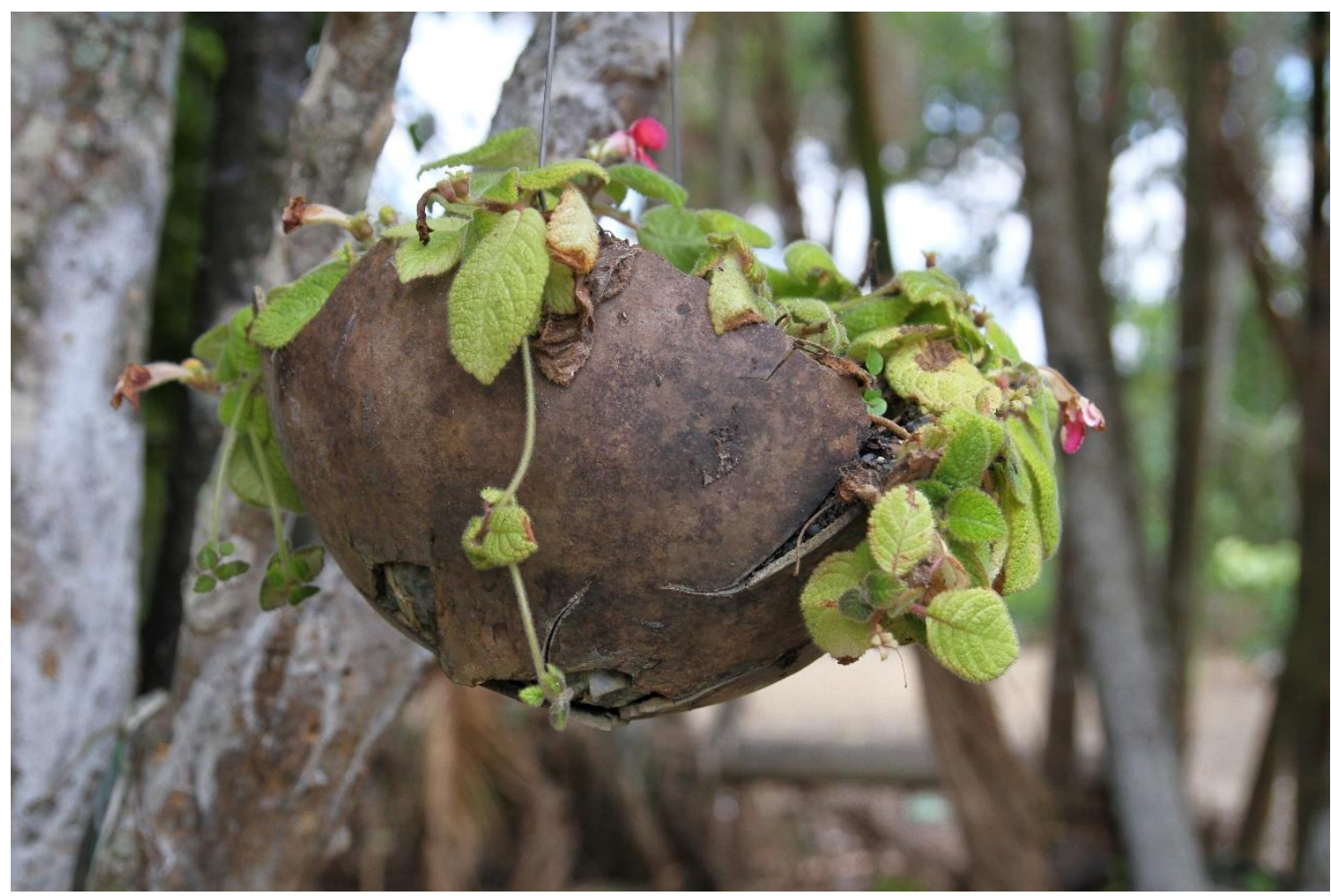

Foto 3 - Nas casas ribeirinhas as cuias pitingas são usadas para variadas finalidades. Com auxílio fios de arame, barbante e outras fibras, transpassados por dois pequenos furos, elas são penduradas e servem como vasos suspensos para quintais e varandas. Frequentemente, mudas de plantas e o próprio vaso de cuia são doadas e trocadas entre parentes e vizinhas. Autor: Carlos de Matos Bandeira, 2014. 


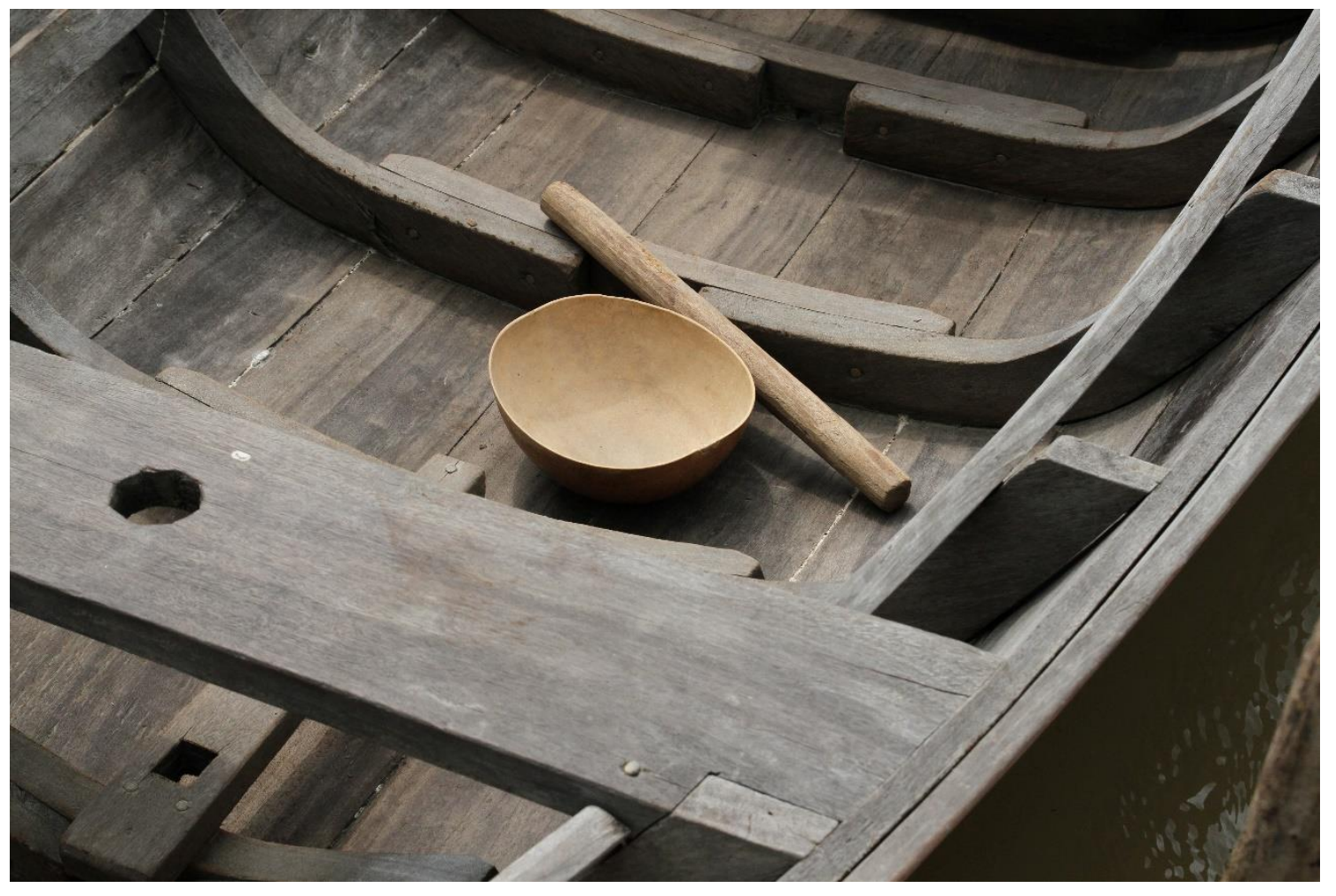

Foto 4 - Carregar uma cuia na canoa é providencial para navegar nos rios e lagos da região. À medida que porções de água entram na embarcação, o/a navegante alterna-se entre o remo e a cuia, que é usada para coletar e despejar a água de volta ao seu curso. Autor: Carlos de Matos Bandeira, 2014. 


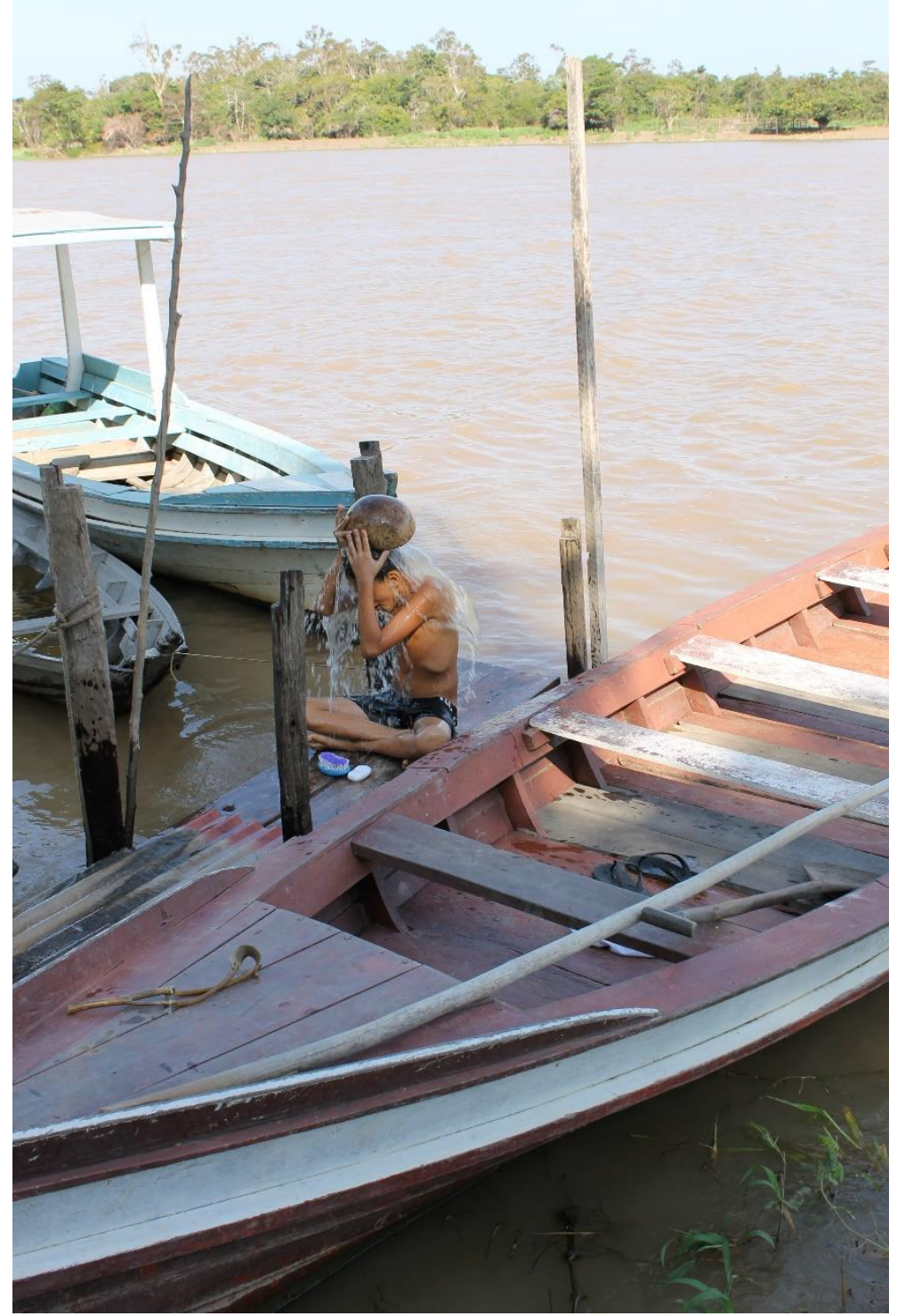

Foto 5 - Tomar banho de cuia na beira é um hábito recorrente na vida ribeirinha, e não só nas residências desprovidas de água encanada! Normalmente, é ao amanhecer e no cair da tarde que as pessoas se dirigem para o porto de casa a fim de se banharem. Sobre uma ponte de madeira ou dentro da canoa, já costumam encontrar sua cuia abastecida com escova e pedaços de sabão. Autor: Luciana Gonçalves de Carvalho, 2011. 


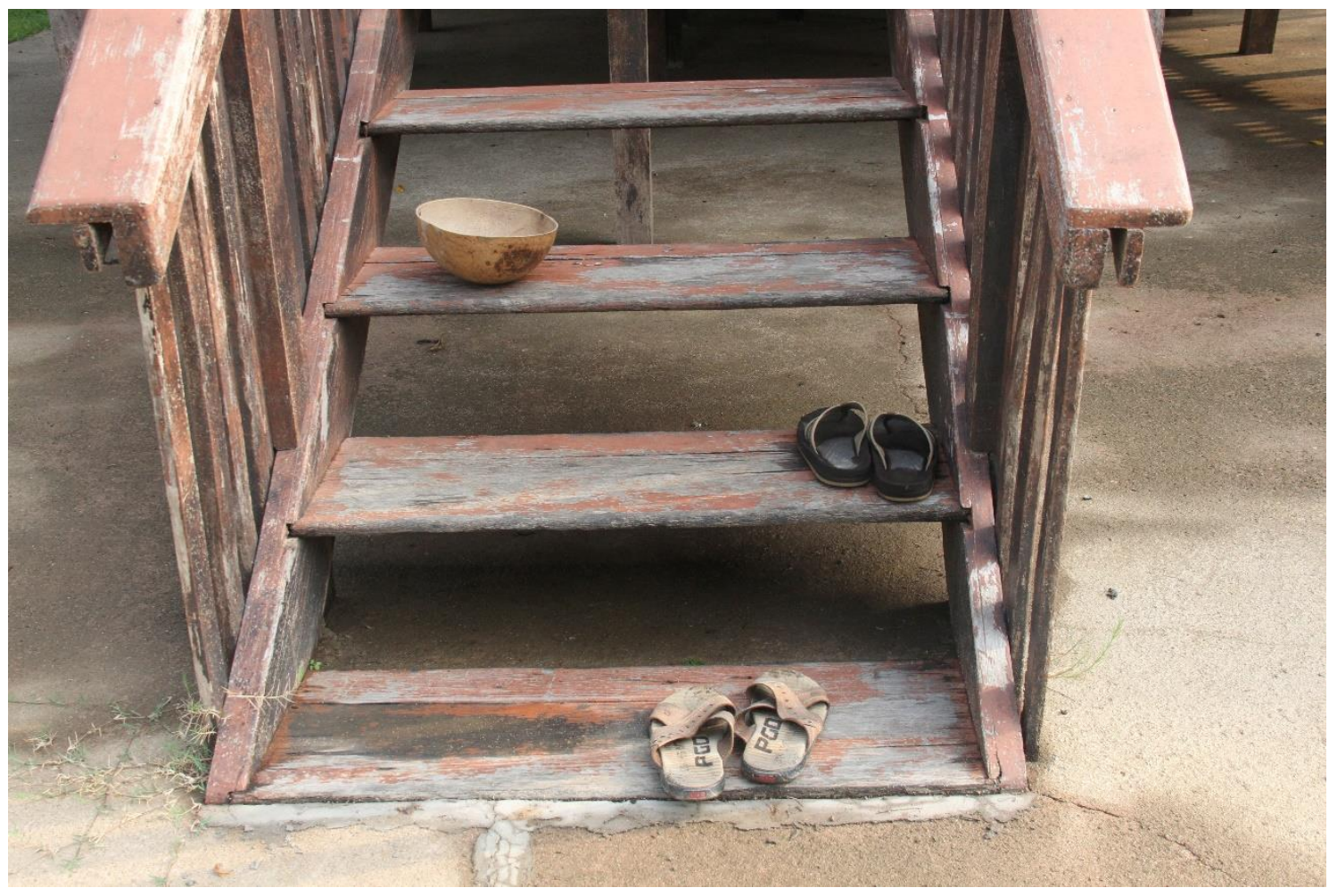

Foto 6 - Quem caminha descalço sobre o assoalho das casas da várzea usufrui a maciez e o frescor do piso de madeira, que contrasta com o calor amazônico. Para mantê-lo asseado e confortável, é essencial deixar os calçados na entrada. Quando toda a família está no lar, é comum notar uma fileira de sandálias nos degraus das escadas que dão acesso às portas. Autor: Carlos de Matos Bandeira, 2014. 


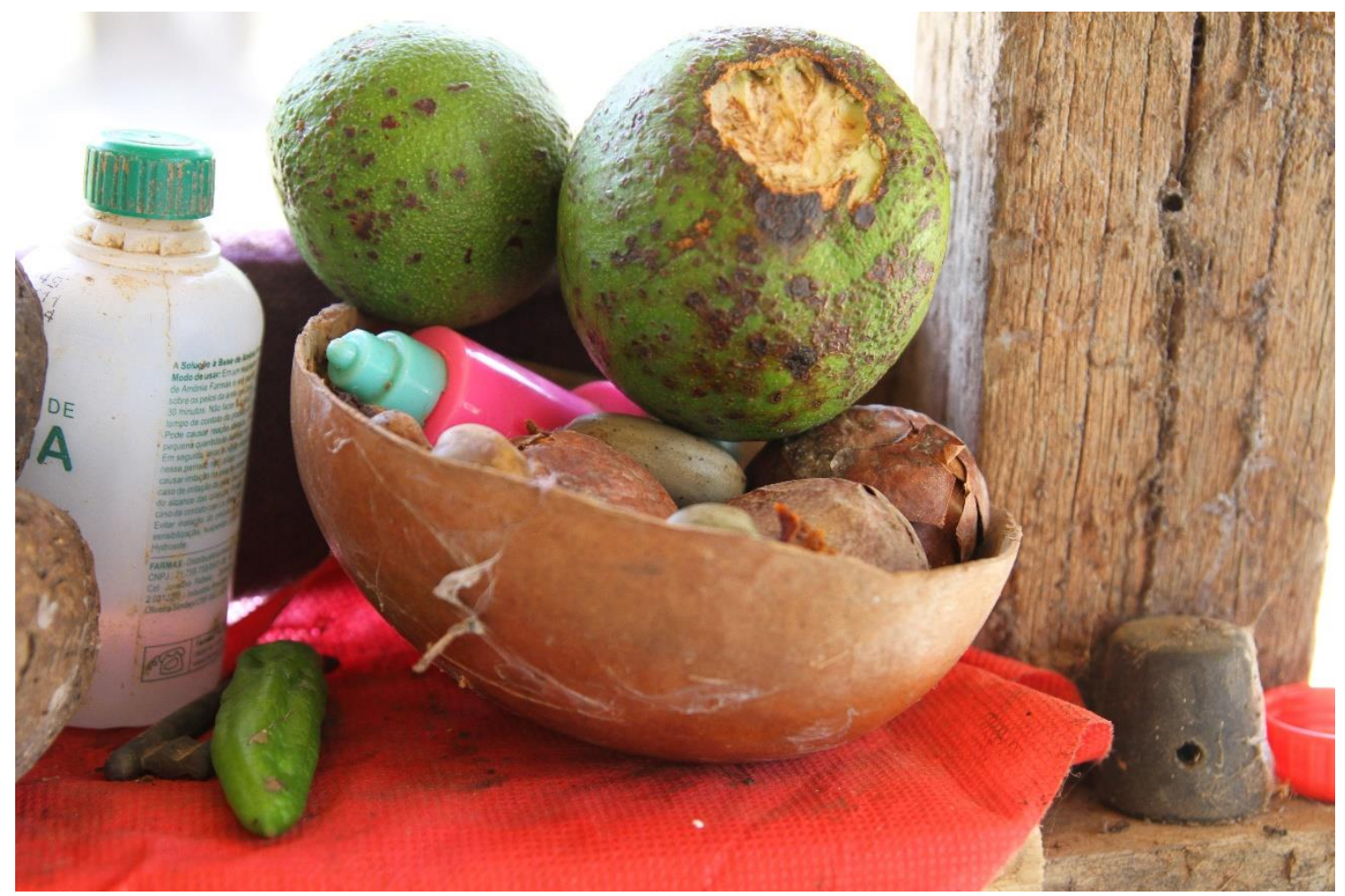

Foto 7 - "Naturalmente, de primeiro, os índios estavam precisando de recipientes, repararam no fruto de casca dura, criaram a primeira cuia"

- assim escreveu Mário de Andrade em 1939. Suas palavras são ainda atuais, nas moradias das várzeas de Santarém. Autor: Carlos de Matos Bandeira, 2014. 


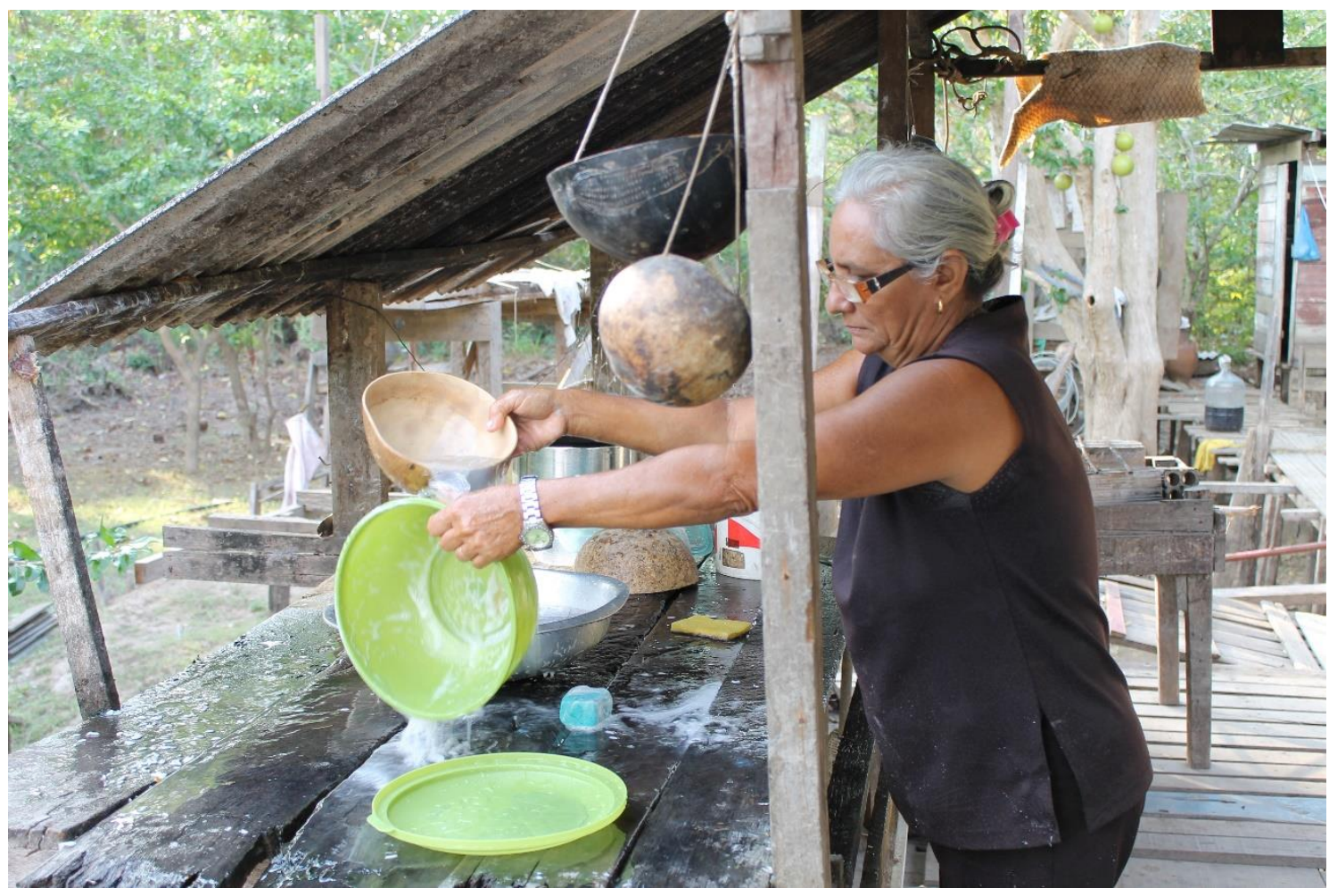

Foto 8 - As cuias também são boas para auxiliar na lavagem das louças

e, por isso, não podem faltar no jirau de Marta Maduro. Enquanto umas, penduradas, guardam o sabão e a esponja, outras são usadas para coletar e verter água limpa de uma bacia para o enxágue dos objetos ensaboados. Autor: Alexandre Nazareth da Rocha, Centro do Aritapera, 2011. 


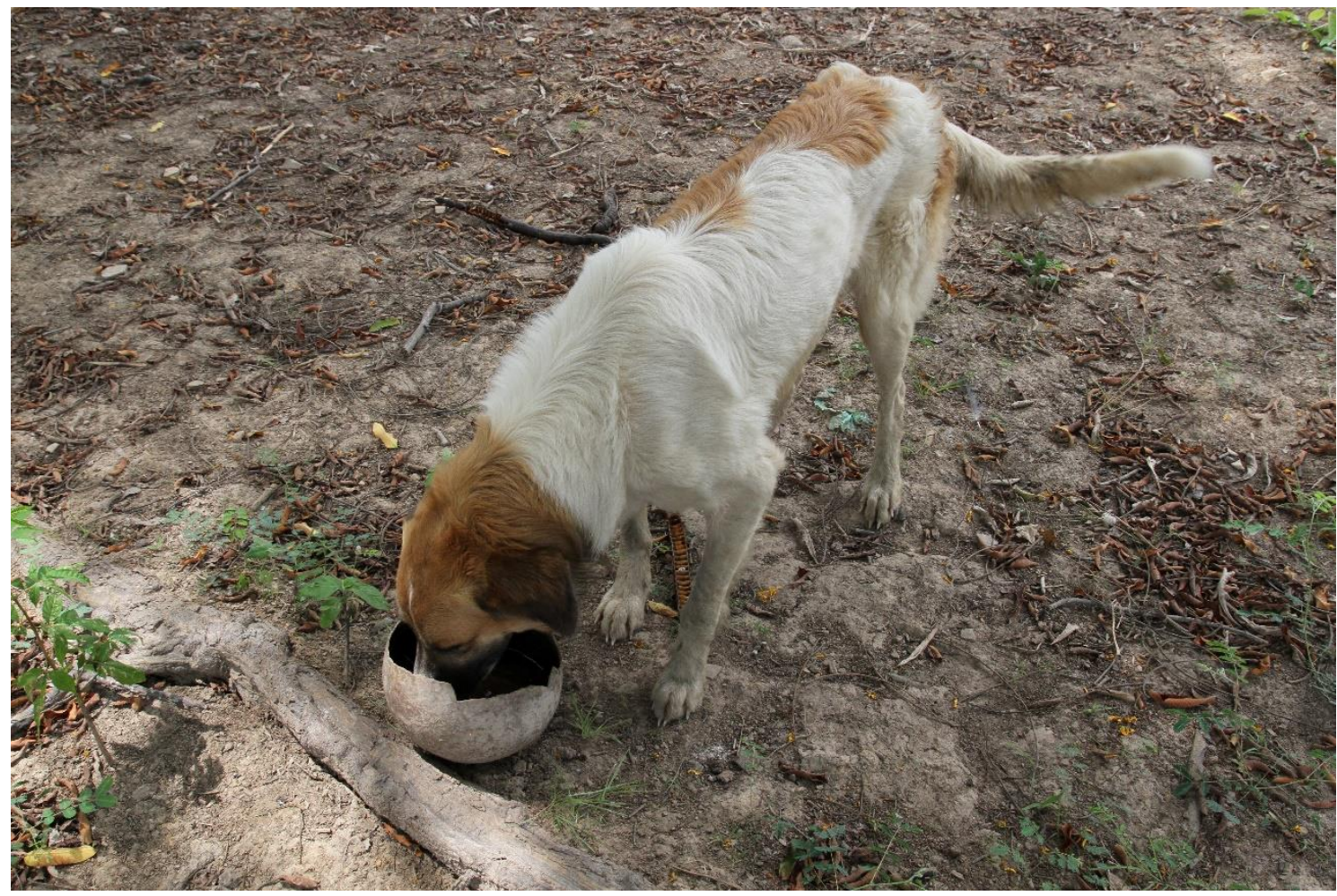

Foto 9 - No quintal, enquanto as galinhas e outros animais se alimentam

do bucho do fruto da cuieira, o cão mata a sede em uma cuia de imperfeita aparência, devido à sua borda quebrada, mas de perfeita serventia. Autor: Carlos de Matos Bandeira, 2014. 


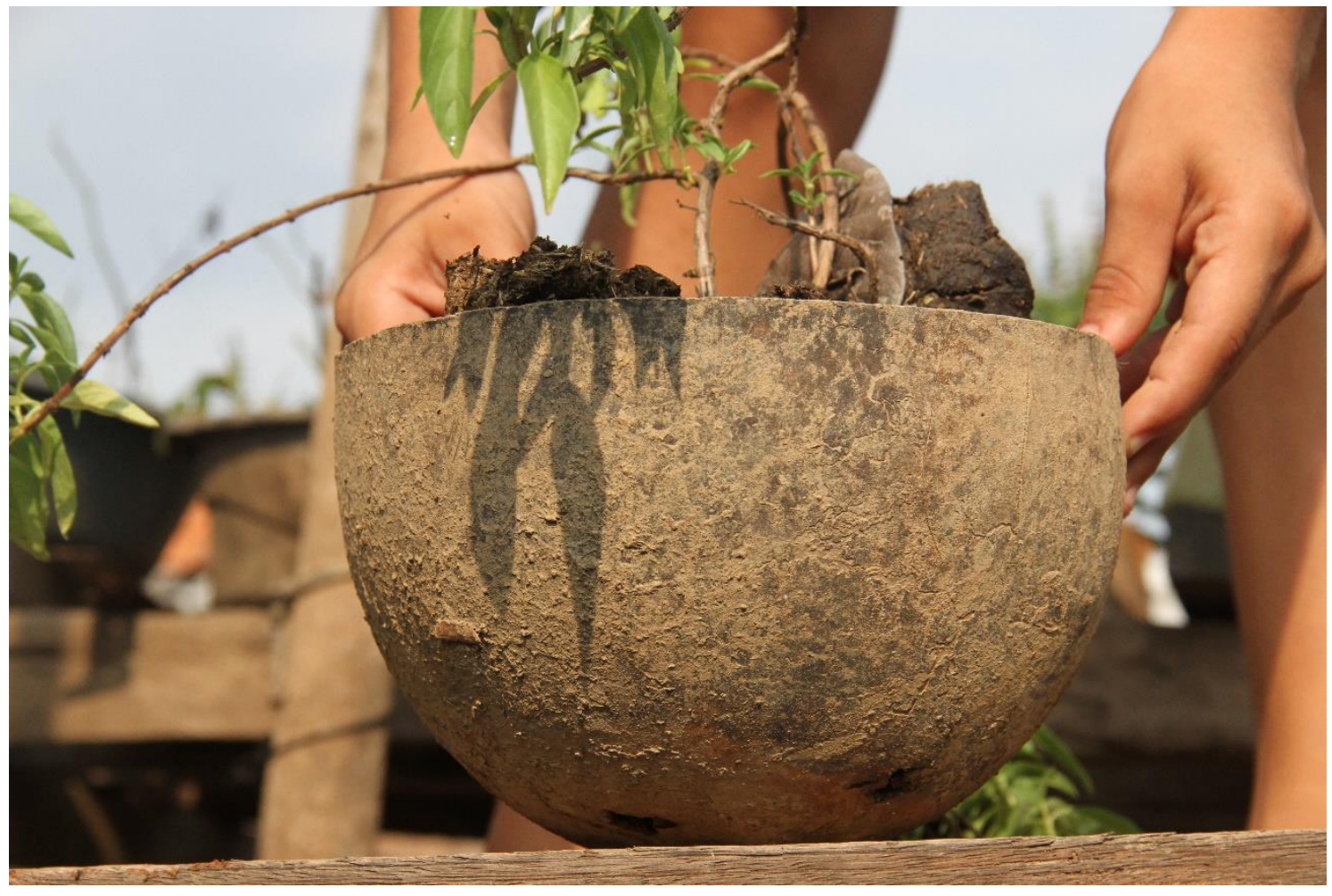

Recebido em 2 de julho de 2019.

representa, na região do Aritapera, a fecundidade desse objeto. Do fruto da cuieira nada se perde. Se sua retirada não prejudica a árvore, tampouco seu corte o transforma em objeto inanimado, uma vez que, de múltiplas maneiras, se conecta à vida de humanos e não humanos. Autor: Carlos de Matos Bandeira, 2014.

Aceito em 29 de janeiro de 2020. 


\section{Referências}

ANDRADE, Mário de. A cuia de Santarém. Suplemento Literário de Diretrizes, Rio de Janeiro, ano 2, n. 20, nov. 1939.

CARVALHO, Luciana Gonçalves de (org.). O artesanato de cuias em perspectiva - Santarém. Rio de Janeiro: Iphan, CNFCP, 2011.

FERREIRA, Alexandre Rodrigues. Memoria sobre as cuyas. Revista Nacional de Educação, 6: 58-63, 1933 [1786].

HARTMANN, Tekhla. Evidência interna em cultura material. O caso das cuias pintadas do século 18. Revista do Museu Paulista, 33: 291-302, 1988.

LÉVI-STRAUSS, Claude. O pensamento selvagem. Campinas: Papirus, 1989.

PAZ, Octavio. "Ver e usar: arte e artesanato". In: Convergências: ensaios sobre arte e literatura. Rio de Janeiro: Rocco, 1991.

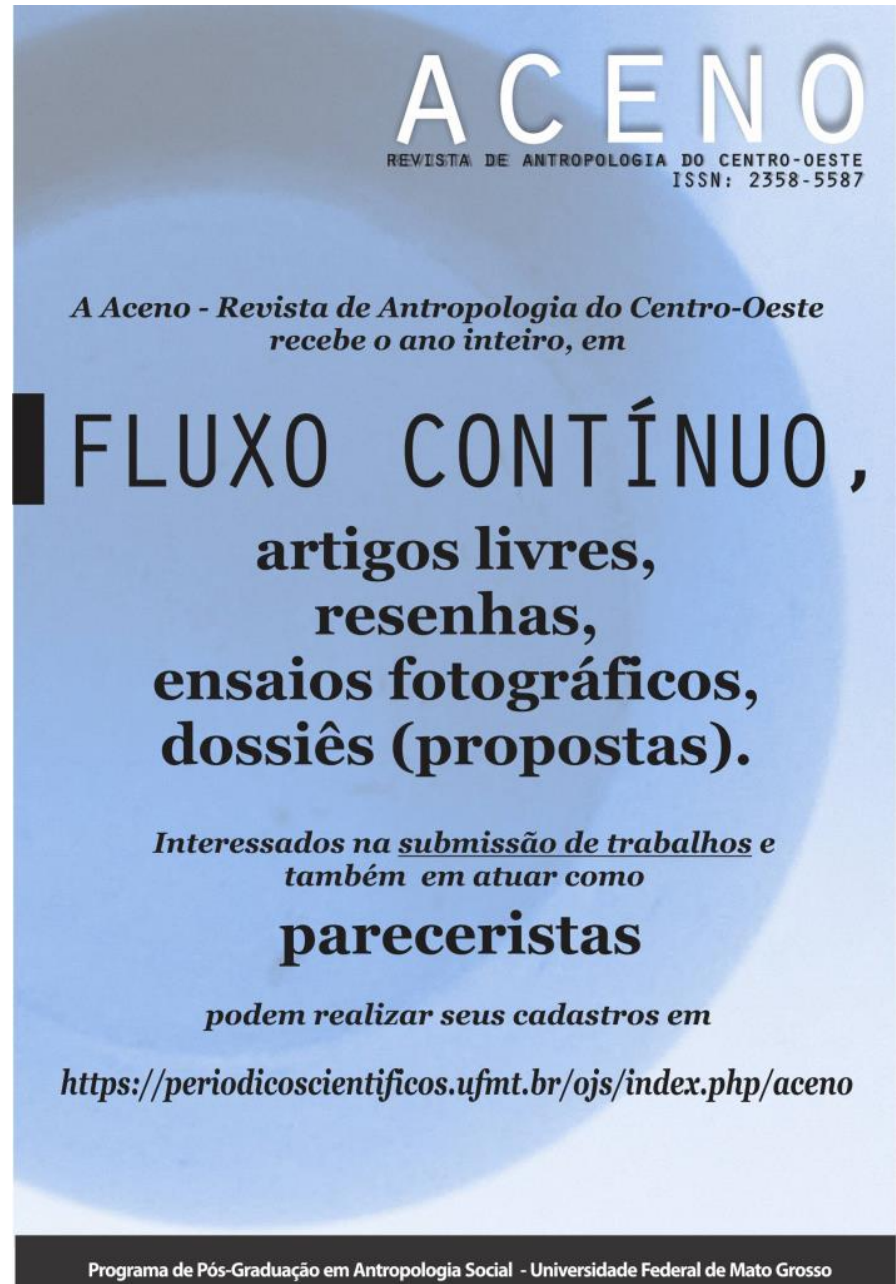

